\title{
Healthy competition: A qualitative study investigating persuasive technologies and the gamification of cycling
}

\author{
Paul Barratt \\ Department of Geography, Staffordshire University, Leek Road, Stoke-on-Trent, Staffordshire ST4 2DF, United Kingdom
}

\section{A R T I C L E I N F O}

\section{Key words:}

Cycling

GPS

Technology

Gamification

Applications

\begin{abstract}
A B S T R A C T
Changing socio-technical practices occurring within cycling are leading the pursuit, and its participants, to become ever more embedded into the networked digital world. GPS enabled mobile-technologies have introduced a new element of competition into recreational riding, whether on the road, competing over timed virtual segments, or online dissecting and comparing the data that has been logged and shared via dedicated ride-logging applications. In order to understand these technologies qualitative study using reflective diaries and semi-structured interviews has been conducted with experienced club cyclists who had fully experienced the effects of their arrival. These riders claim that the applications influence their route choice and motivate them to cycle more frequently, and at a greater intensity although the engagement changes over time. This paper explores how this increased motivation to exercise and compete is instigated, manifested and maintained in the everyday practices of cyclists, as well as the negative consequences of gamification.
\end{abstract}

\section{Introduction}

In recent years a persuasive and pervasive socio-technical system has been incorporated into the everyday kit of an increasing amount of cyclists. Whereas past cyclometers relied on the mechanical assistance of a spoke mounted rivet to calculate distance, today's cycling computers recruit a network of satellites, GPS units, computers, smartphones and applications, all of which require software platforms. These devices, and their scripts, augment the ride structuring and shaping connections which can be engaged with both on and off the bike. Perhaps the most notable difference wrought here is that the immaterial and intangible (post-practice) bike ride becomes, through GPS and biofeedback tracking, a material artefact. A bike ride is no longer something that just happened, a memory, a calorie deficit to be annulled, it endures, it becomes tangible - it is a record in a training log, a time on a leaderboard, a route to be shared amongst friends and strangers. A bike ride has become through quantification a manifest digital achievement, or as will be explored throughout this paper, a package of achievements each designed to motivate the rider and 'enhance' the cycling experience.

To some the new intelligent digital materialities of cycling erode the value of its culture and practices by creating a new virtual form of competition that detracts from the sociability of a recreational group pursuit causing rides to fragment and unexpected changes in pace (Dansie, 2013; Sparkes, 2013). Yet despite numerous critics, cycling applications, and the technology that supports them, has over a short period of time had a huge impact upon the pursuit. The devices and rituals around them have become embedded in many cyclists' everyday practices. Whilst others have investigated how self-monitoring becomes embedded and normalized in everyday practices (see Pantzar and Ruckenstein (2015)), this paper provides a rich and contextually sensitive empirical study which permits a more nuanced picture of how everyday technologized practices are consequential in terms of health and well-being. In line with the ethos of this special issue on health promotion and exercise experience this paper delves into the practice of cycling to explore processes of change with an emphasise on the role of technology. The everyday manifestations of change occurring both on and off the bike are investigated in relation to their impact on the active lifestyles of cyclists. This will help in understanding the dynamics of engagement, a crucial element in gamified health interventions (Coombes and Jones, 2016), as well as the scope for certain health promoting practices allied to the new technologized context of cycling.

\section{Cycling for health}

Cycling, like swimming and running, is popular in our time-pressed world because it can be done alone or in small groups free from the constraints of social co-ordination (Sutch et al., 2015). Cycling as an alternative form of mobility to the automobile has received renewed attention in relation to its numerous health and sustainability benefits (Woodcock et al., 2014; Fishman et al., 2015). Cycling is the third most popular sport in the UK with $38 \%$ of the British population considering themselves to be current cyclists (Mintel, 2016) A higher number 50\% would consider cycling in the future, $27 \%$ of which claiming to be lapsed cyclists who have ridden in the past (Mintel, 2016). Research 
indicates that $43 \%$ of the population claim to own or have access to a bike (Sport England, 2013) and although access does not mean usage, it does suggest a potential to do so. Cycling participation growth has been strong in recent years and although men's participation has begun to plateau, female participation has grown 6\% between from 2013 to 2015 albeit from a lower base level (Mintel, 2016). These figures present a compelling case that cycling participation and the health benefits that accompany the activity is ripe for growth for leisure, exercise or as a means of personal transportation. The cycling club members sampled for this study cut across many of the pursuits various sub-sections consisting of riders describing themselves as recreational, racers, commuters, timetrailists but also those who were affiliated to clubs but mostly rode alone or in small informal groups.

The figures on the growth of cycling tracking devices are obscured within market research data due to the popularity of smartphone apps that can perform many of the dedicated devices functions (Mintel, 2015). Strava is the most popular of these apps and hence forms the case study for this investigation. With approximately $73 \%$ of the British population owning a smart phone (Ipsos MORI, 2016) there is a great deal of potential for engagement with health and tracking apps in addition to those cyclists already tracking their rides. The ride tracking app Strava reported that British riders logged 23 million rides via their app in 2015, approximately 8.9 million of these were logged as commutes a weekly average of 172,000 ( Strava, 2016). These figures beg the question as to whether ride logging apps play a role in motivating and/or sustaining active journeys. There are now well over 31,000 health related apps on the market (Essany, 2013). This and the identified lack of research into their value (Payne et al., 2015) provides further impetus for studies that explore the everyday lived experience of those using them. Whilst the burgeoning of app use and ride logging cannot solely explain increases in cycling participation the quantification, gamification and related sociability of these apps is likely to enhance the appeal for lone or group riders.

Commuting by cycle represents the main form of transport for 741,000 people (ONS, 2014). The Department for Transport (DfT 2014: 11) estimate that "for every $£ 1$ of public money spent [on cycling], the funded schemes provide $£ 5.50$ worth of social benefit". These benefits are mostly accounted for by improvements to health, for example, the cost savings for employers due to fewer missed days and savings made by the NHS (Department for Transport (DfT), 2014). Given the noted benefits to the health and well-being of citizens, it stands to reason that seeking to understand the contemporary practice of cycling and cyclists is vital to maintain and promote the activity (Spinney, 2011; Latham and Wood, 2015). This paper has particular relevance here by illustrating ways in which apps may help bridge the barrier between policy and behaviour change through gamification.

\section{Technologized lives and leisure}

Scholars investigating active outdoor pursuits such as cycling (Spinney, 2006; Jones, 2005) climbing (Barratt, 2011; 2012) and walking (Michael, 2009; Shove and Pantzar, 2005), recognise that the relations between bodies and the activities' respective technological material artefacts alter and enhance environmental engagements and experiences by extending bodily capacities both physically and mentally. In regard to cycling, two articles illustrate these often abstract material relations particularly well. First is Spinney's (2006) paper on cycling up Mont Ventoux. This paper focusses upon the hybrid subject of a cyclist overcoming the challenge of a mountain - the kinaesthetic sensations of the body and bicycle in unison being vital to the meanings attributed to the practice and sense of place. A second paper by Jones (2005), based on a routine commute across Birmingham, UK, emphasises how the city is uniquely remade through the cyclist's performance. These two papers eloquently unravel the situatedness of the practice and offer a great deal of insight into the pleasure and pain of cycling as a unique form of active mobility. The analysis of active participation and the meanings produced as a hybrid mobile subject are deemed essential to exploring embodied practice and the meanings people attach to both place and experience. Accordingly by exploring the lived experiences of hybrid spaces of cycling this paper seeks to extend these arguments by demonstrating the mediating effect of mobile technologies, in relation to health and exercise.

The socio-technical practices of cycling, like any other everyday activity, are subject to change (Shove and Pantzar, 2005). In cycling a new layer has for some been added to the practice, a digital connectivity to the landscape and wider social communities through the use of GPS trackers and partner applications. Marked changes in practice are apparent to those who subscribe to the technologies, or ride with those who do - as the data above from Strava, Ipsos MORI and Mintel suggests this is a large and increasing proportion of the cycling population. Indeed if the alpinist or urban cycle commuter theorised in Spinney's and Jones' papers were to straddle their cycles today, equipped with a GPS enabled computer or smartphone, their experiences and performances, notwithstanding widely differing contexts, would be mediated and identifiably different as a result. Little attention has been given to the role, influence and implications of mobile connected technologies in such pursuits. The work of Michael (2009) and Butryn and Masucci (2009) provide notable exceptions outside of cycling detailing peoples' qualitative lived experience with technology during outdoor leisure. This paper provides further empirical detail based upon contemporary cycling practices and technologies, whist contributing to a growing body of research asserting the importance of observing practices more closely to inform policy that promotes healthy active lifestyles (Jones, 2005; Spinney, 2011; Latham and Wood, 2015).

\section{Methodology}

The empirical content for this article is draw from semi-structured interviews with cyclists, reflective diaries kept by experienced club cyclists new to GPS trackers and ride logging, as well as the authors auto-ethnographic experience as a regular road cyclist. Twenty club level cyclists based in Staffordshire, Cheshire and Derbyshire were interviewed (2012-2015), the sample stratified by age and gender broadly in line with cycling participation rates (Sport England, 2013). The sample comprised of club cyclists for several reasons, first and foremost it ensured that they were active and committed to cycling at a recreational if not competitive level. Second, being part of a cycling group ensured that the sample could reflect upon the use of apps from both their own perspective and that of other club members, the contradictions and differing experiences ensuring the complexity on engagements to be captured. Furthermore, the formal club structure facilitated the recruitment of a stratified sample which would have been more difficult to obtain by approaching individual cyclists or those who rode in informal networks.

Despite the commitment that the title 'club cyclist' suggests, all of the participants described barriers to their riding including inclement weather, safety fears, convenience, available time, motivation and energy levels. These are issues that are reported to influence cycling participation in the wider population (see Pooley et al. (2011)). It should therefore not be assumed that club cyclists differ widely from other cyclists or potential cyclists other than the formal structure of their respective clubs. However, unlike their causal counterparts the cyclists in this study are part of an established social community of cyclists with opportunities to compete in organised time trails and races. These are riders who do not require an app to maintain contact or compete, yet, as the paper will discuss cycling apps have become an important part of their individual and collective activities.

Gender representation was also sought in the sample for this study as cycling is a highly gendered pursuit in the UK (Steinbach et al., 2011). The research also sought to begin to explore the potential differences in the manner that men and women engaged with cycling 
technology. In order to understand these technologies and the practices becoming associated with their use I needed to talk to those who had fully experienced the effects of their arrival. Riding with some of my respondents vastly aided my understanding of their complex and nuanced relationship with the apps and technology that they used. All of my respondents did or had used mobile tracking devices and apps although there was a diversity of opinions surrounding ongoing engagements with the technology.

The methodology employed for this study, rather than relying solely upon personal experience and the methodological dilemmas that such approaches raise (Mercer, 2007), has sought to understand cyclists' mediated engagements through talking, and on occasion, cycling with them. This approach engages directly with calls to move beyond the flattening 'pro-forma social science treatment of interview transcripts' (Lorimer, 2005: 87) whilst recognising the value of a creative encounter undertaken within the context of the activity (Hitchings and Latham, 2016; Spinney, 2011). Experiencing technology first hand in the context of a group ride facilitated closer scrutiny of transcripts and reflective diary accounts provided by those becoming accustomed to digital cycling practices.

\section{The digital cyclist}

It can be accepted that the geographies of everyday life are increasingly mediated and augmented by technology (Thrift and French, 2002). Thus an understanding of contemporary cycling technology is vital in order situate the changing practices of the pursuit. Innovations in bike design aside, this investigation focuses upon what cyclists' refer to as their cycle computers (see Fig. 1). Cycle computers are handlebar mounted devices used to monitor, process, display and record performance data. A range of data can be displayed typically including, speed, average speed, heart rate, cadence, power, gradient, altitude. Although some computers measure speed and

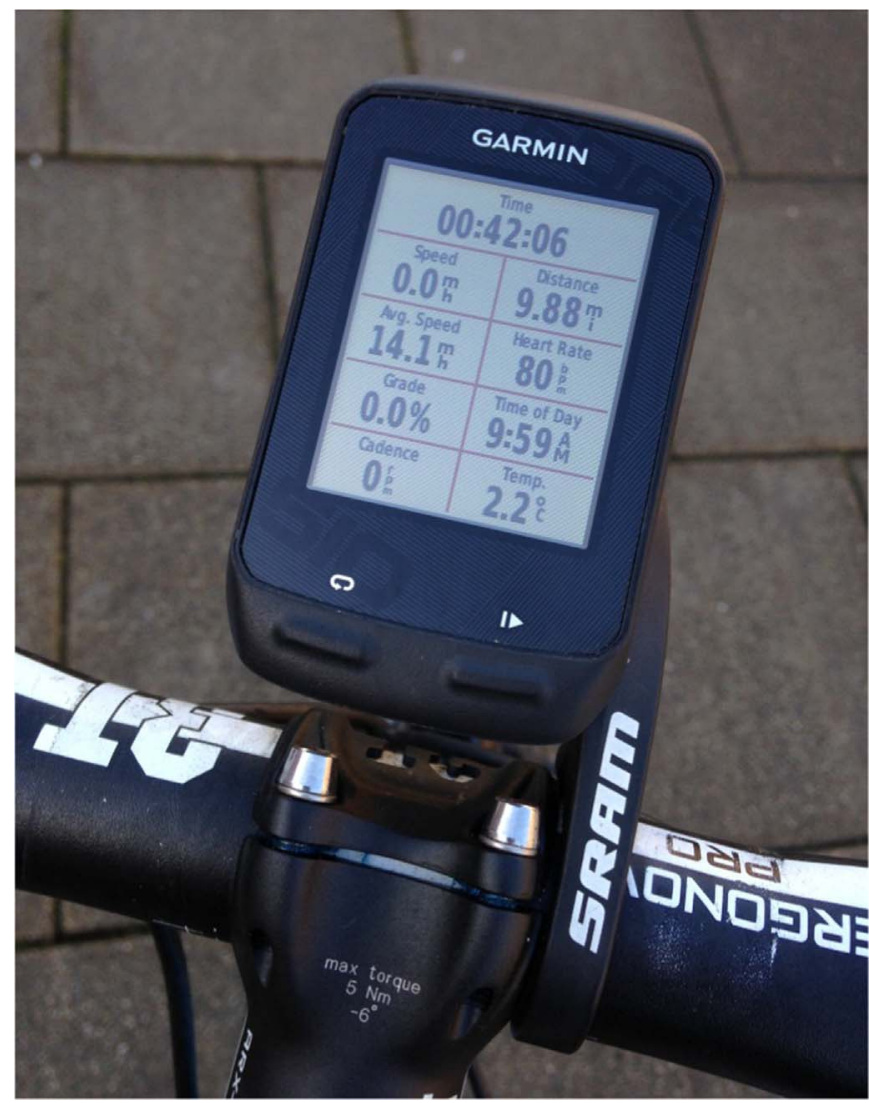

Fig. 1. Garmin Edge 510 Cycle Computer. (Source: author's own). distance via sensors that record wheel rotations, increasingly this is calculated via GPS functionality. It is this feature in particular, that has led to widespread changes in the pursuit through dedicated ride logging applications to which devices and data are paired.

The role of the cycling computer and the data that they process, present and store has been extended from the activity of cycling, creating a new digital community of cyclists with associated practices. A ride that has been tracked by GPS and recorded can be downloaded and quantified in numerous ways via a ride logging application. There are a number of these available, the most common being, Strava, MapMyRide, Garmin Connect, Endomondo and RidewithGPS. During the ride logging process the data from the ride undergoes a number of transformations. The route and its elevation are mapped along with a read-out and analysis of the performance, including speed, duration, heartrate and power (See Fig. 2). Some applications such as Strava also have a competitive element whereby virtual awards are allocated based upon timed segments of the route such as popular climbs or sprints. The bike ride is transformed from something that just happened into something tangible. This is an important feature of the changes occurring in cycling because before the use of GPS and ride logging apps only those who kept a training log or formally raced had any sort of record of their rides.

Through ride-logging the bike ride lives on. It is no longer an immaterial memory or entry in a training log the ride becomes material, to borrow from Actor Network Theory (ANT), in the form of combinable inscriptions. To Latour (1999: 306) Inscriptions are "all types of transformations through which an entity becomes materialized into a sign...”. It is this quantification and materialisation of the ride that provides the platform for the gamification of the pursuit. The persuasive scripts associated with apps such as Strava in conjunction with the mobile-technologies of cycling have created a narrative for place and experience for cyclists, and although the narrative is free for personal/group interpretations, it plays a powerful part in influencing the practice. This was eloquently termed the 'digital imperative' by one of my interviewees who found it curious that the club rides that he was involved with had become governed by an app and assemblage of technology to which he himself did not subscribe. The implications of this ostensible digital imperative, fuelled by quantification, classification and competition, is detailed below after a brief introduction to the application Strava and the concept and purpose of gamification.

\section{Gamification and persuasive technology}

Strava and its associated platforms and devices could be considered technologies designed to change attitudes or behaviours through persuasion and social influence (Fogg, 2003). Strava's was conceived to enhance the practice of solo riding in order to provide the social camaraderie of a team whilst training alone (Wallace, 2012). Strava's mission statement argues;

"Strava lets you track your rides and runs via your iPhone, Android or dedicated GPS device to analyze and quantify your performance. Strava makes fitness a social experience, providing motivation and camaraderie even if you're exercising alone" (www.strava.com/ about).

Whilst Strava does not explicitly state a desire to change behaviour, the role of the app for motivational purposes has always been central, and is an element that has been refined to maintain and increase its draw. When examining the methods used by Strava to quantify the ride strong parallels become evident between the key features of the app, and the mechanisms of gamification. These are the mechanisms that have a persuasive influence on the cycling practice of its users. It does this via the gamification process, by applying game mechanics and game design in order to motivate people to achieve their goals. Gamification taps into the basic desires and needs of the users which revolve around the idea of status and achievement (Fogg, 2003). 


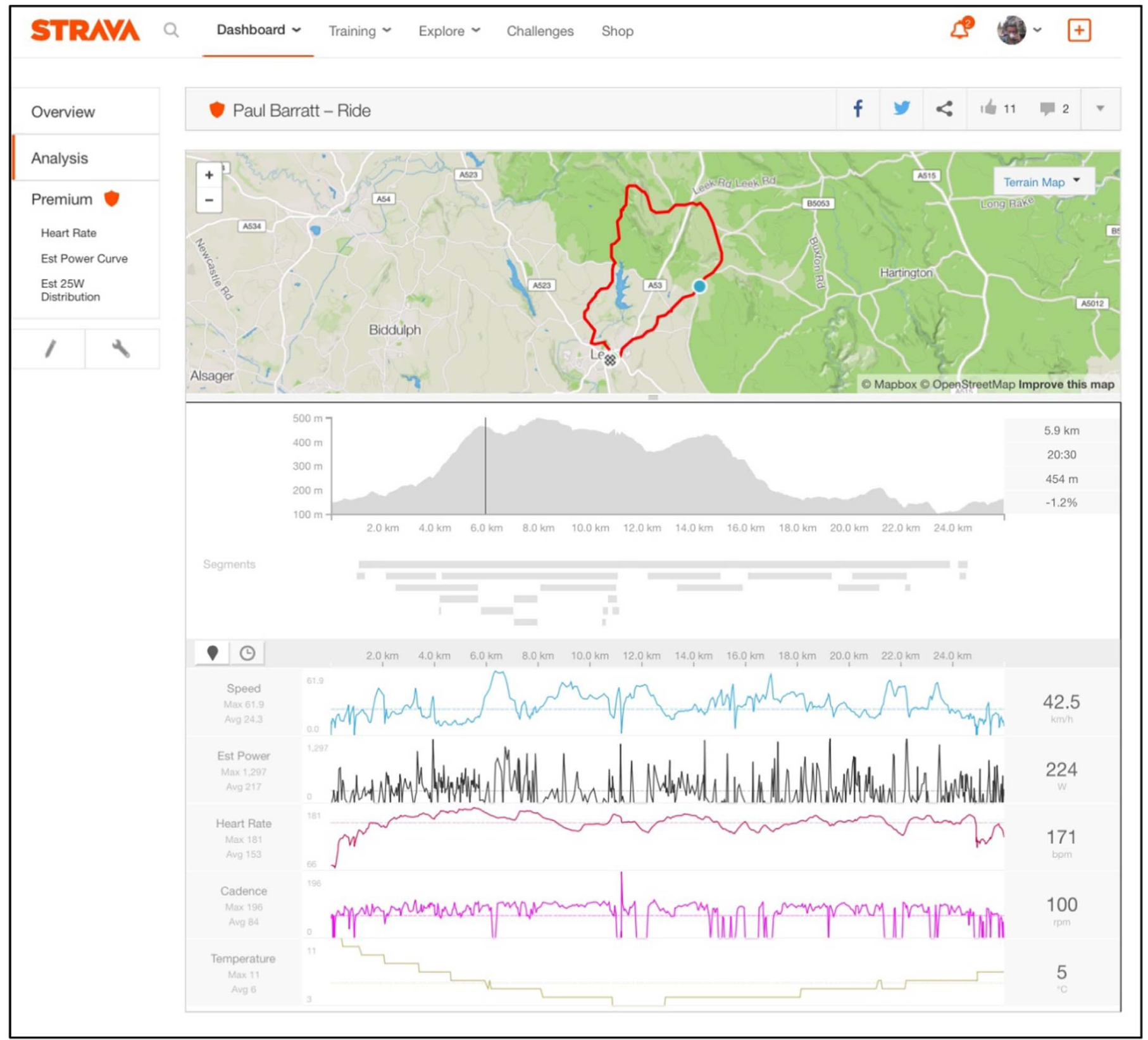

Fig. 2. Strava mapped ride. (Source: http://www.strava.com).

Gamification mechanisms typically include the following;

- Points

- Badges

- Leaderboards

- Progress bars

- Performance graphs

- Quests

- Meaningful stories

- Avatars

- Profile development

(Source: Sailer et al., 2013).

Whilst we might expect these in the virtual world of computer gaming, the concepts above are increasingly applied to everyday practices including advertising, shopping and in relation to this paper health and exercise. Whilst Lister et al. (2014) stress that there is abundant use of gamification in health and fitness apps, they identify a lack of in-depth study and evaluation into the practices surrounding them. Likewise Hamari et al. (2014) point to the potential of gamification to change health behaviours. However they identify that this claim is based upon a paucity of highly context specific research. Strava provides an ideal case study of gamified augmented reality and this paper intends to add qualitative insight into the lived experience of cyclists in a newly technologized pursuit exploring the health benefits that come through engagement. A significant feature with cycling apps is the mobility of the technology, because it is argued that technology is likely to be more persuasive if it is mobile and can provide "current, contingent, and coordinated information” (Fogg, 2003: 183), the visuality of the app increasing this effect (Verhoeff, 2012). The following section turns to the experiences of the cyclists in my study using their own words to illustrate how Strava and gamification influences their practice of cycling and the consequences of this for their health and well-being. 


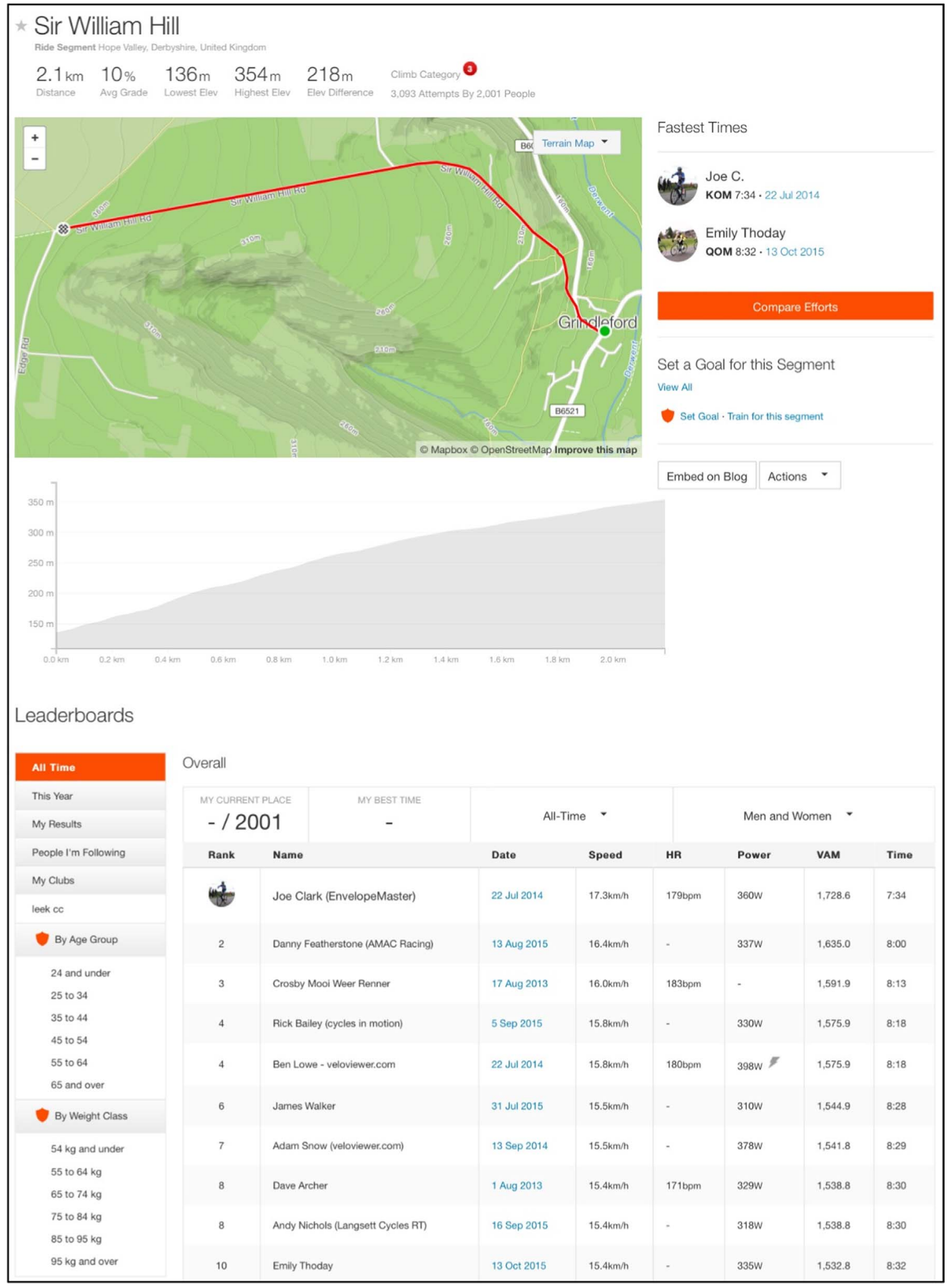

Fig. 3. Strava augment page and leaderboard. (Source: http//:www.strava.com).

\section{Persuasion and motivation the role of segments and competition}

"I don't take it too seriously but I enjoy it all the same. I know that I'll never climb like (Alberto) Contador meaning that KOMs are mostly off limits, but I'll have a wry smile if I beat someone who should by all intents and purposes be faster than me." (Dave 42)

The segment dictated the narrative of many interviews and diary entries during this study representing the central gamified element of Strava. A segment is a predetermined section of road over which the rider is timed via GPS. Segments can be very short or long, uphill, 
downhill, flat or varied. Some Strava segments are created automatically by the app pulling geographic information from maps for profile and naming purposes. Others are created and named by users to act as a challenge for themselves and others. Each segment has a leaderboard (see Fig. 3) associated with it noting all the best times logged by Strava athletes (the term used by Strava for its users not withstanding rider type or ability) who have ridden the segment. Riders placing within the top ten receive a virtual trophy which they are notified of in the ride overview. A rider posting a best personal time outside of the top ten will receive a notification that they have achieved a personal record on the segment. Riders who top the leaderboard receive the title of KoM (King of the Mountain) or QoM (Queen of the Mountain).

The drive to compete whilst cycling is often strong and Strava provides a platform where users can compete without the potential anxieties that traditional forms of racing can induce (Leary, 1992). The cyclists in this study embraced this competitive outlet and were drawn into this virtual world of competitiveness in varying amounts and for differing durations. Most riders acknowledged their enjoyment of the competitive elements of Strava - there spaces of cycling being perpetually recast via the gamified script supported by the app (Kirsch, 1995). They enjoyed seeing their name on leaderboards and/ or out-competing their friends or indeed their heroes form the professional peloton. This was regarded as an extension of the friendly rivalry that existed during group rides - furthermore a rivalry now available to the solo rider. Riders disclosed that as a direct result of this competitive element Strava had led to increased intensity on certain sections, or for the entire duration - every ride became an opportunity for competition. Several also stated that the frequency of their rides had increased in order to remain or become more competitive at the app. Routes rather than being selected for riding preference were often chosen or adjusted to include segments. Riders went so far as to alter routes to take advantage of favourable weather conditions for a particular segment. For example, as Louise describes below a strong following wind.

"Weather has always been factored into route planning, good weather calls for scenic views, frost and it's main roads, if it's windy I'll think about the exposure or where I'll face a headwind. With Strava, wind is a big influence - planning and riding. There's no point smashing a segment into a headwind, but I'll try even harder if there's one blowing from the rear!" (Louise 28)

Riders like Louise were drawn in by the gamification and embraced outside assistance which helped them compete on the leaderboards. The use of favourable weather was but one of the more playful elements of riders engagement with Strava offering a performance enhancement that became hidden through the quantification of the ride. My discussions with Louise (and other riders) suggests that every ride undertaken with technology includes a sub-plot of planning in to which the health benefits and healthy habits become part of the aim to ultimately improve on past performances.

Despite, some contradictory comments and active resistance to the lure to compete, all of the riders notwithstanding age or gender that took part in the study had to a greater or lesser extent been influenced in this manner - succumbing to the drive to compete, often reporting significant achievements such as KoMs and QoMs in their reflective diaries. The interviewees who used Strava admitted to being motivated by this feature during recreational rides. Further and beyond this, it emerged that the segment and other competitive elements within Strava were consciously drawn upon to provide motivation. The prime example of this was the use of segments on otherwise mundane journeys including commutes. Gary (33) stated, "I add segments to my morning commute to make it more interesting".

Gary told me how even with Strava the commute had become a little monotonous hence his rationale to add more segments to 'spice it up'. He cited dissatisfaction of the original range of segments that were present on the route whereas others particularly those newly engaged with the app were happy and motivated by existing segments. This was just one of the temporal changes in engagement with Strava documented in the research.

Whilst the segment initially motivates the rider to compete, this draw was claimed to subside to varying degrees amongst the riders interviewed. Reasons given for this included, declining interest in the competitive element of Strava, a segment not warranting or worthy of the riders effort, the rider having already set as fast a time as possible, the realisation that although improvement was possible the increased speed may incur greater risk. Thereafter a broader and longer term persuasion is required to ensure the riders commitment. A different set of tools and gamified elements are required to reinforce the rider's efforts. In order to maintain the attraction of the app and gain more paying subscribers Strava is constantly evolving. Several areas receive regular updates to maintain long-term interest. Three of these areas are discussed below, they are distinct but overlapping namely 'challenges', 'profile development' and 'training'.

\section{Challenges, badges and quests}

Whilst the segment maintains riders' shorter-term attention Strava also employs longer term challenges which test the cyclist's stamina and commitment. Strava's 'Challenges' use a number of gaming mechanisms mentioned above, notably, quests, progress bars and badges, although the completion of a challenge will also likely enhance the profile development and related performance graphs. Strava's challenges are based around distance, time spent riding or ascension. For example, Gran Fondo Challenges, challenge the rider to ride 100k in a single ride. There are also monthly challenges based upon accumulated distance or ascension each with associate leaderboards. On completion of the challenge a pin badge is placed within the riders virtual 'trophy room'.

Although there are many challenges throughout the year, one that gains a great deal of attention and 'kudos' (Strava's social endorsement function) for completion is the Rapha Festive 500. The Festive 500 challenges riders to ride $500 \mathrm{~km}$ in the period between Christmas and New Year. The timing of the challenge adds to the both the draw and the difficulty. On the one hand riders are likely to have time off work providing the opportunity to complete the challenge. Whilst on the other hand the season will throw up a number of issues including, the weather and available daylight hours (UK Winter) or conflict with the social and familial responsibilities associated with the cultural practices of Christmas. Mike (46) describes his situation below.

Mike: "There's the Rapha Festive 500, I'd like to do it but the missus would kill me!".

Interviewer: "I can understand why, but what do you do?"

Mike: "You know, these things take time, they take you out of the home, if you're like me this can take a certain amount of negotiation over Christmas it's a no go - I still ride too much though".

Interviewer: "More so since you started using Strava?"

Mike: "I haven't got the data but yes - a lot more!" [original emphasis].

Familial conflict notwithstanding, many riders complete the challenge and like Mike above admit to putting Strava fuelled riding commitments before other responsibilities throughout the year. Other riders commented how they would 'stick and extra loop on' or add an 'extra climb' to their rides with a specific cumulative challenge in mind - or to ensure their weekly distance bettered that of their peers - the technological surveillance associated with the challenge adding to the digital imperative to cycle.

Riders spoke about enjoying the challenge function stating that they often rode more frequently and for greater durations to complete them. Likewise riders planned routes specifically for challenges including additional hills for ascension challenges or flatter routes for distance when time was of the essence. Riders also emphasised the conflicts that could occur around them in terms of the time taken up and energy 
exerted for their completion. The enjoyment of completing a challenge was often tinged with a self-confessed bemusement and embarrassment that they had been captured by such a simple mechanism which often created friction in other areas of their lives - overwhelmingly in my sample this was amongst the men.

Critical consideration is needed around the gendered implications associated with gamified fitness tracking apps. This study alludes to a gendered demographic, motivated to ride more frequently and for greater duration by an app. This will also have an impact upon those around them. For instance, for those in relationships with familial responsibilities the household balance maybe altered. Whilst the fitness and health of some improve, the opportunities and wellbeing of others is likely to suffer. Nomaguchi and Bianchi (2004) highlight gender disparities in exercise with men tending to exercise more and given the evidence from the interviews and diary entries provided for this study, apps such as Strava will only increase this disparity. Further research is needed to explore this aspect in regard to applications and sport to ensure that policies and schemes that promote engagement with them are not intrinsically gendered further disadvantaging women's fitness or broader position in the home and society.

\section{Profile development}

The 'Athlete Profile' page on Strava is busy with information. The page includes an avatar (profile picture) and cumulative data for riding in terms of distance and ascension by week, month, annually and alltime. A list of recent achievements and activities, links to virtual trophy and challenge pages, a list of riders that are following you and vice versa, are also displayed. There is a list of the bikes used, the biggest rides and climbs achieved, an album of photos taken whilst riding. True to form a rider's cumulative data can be viewed alongside that of other riders, whilst observing their respective profiles providing - an additional element of side by side comparison and competition.

"It [the profile page] tells you whether someone is serious or not. You can tell these things how often or far they ride, if they've logged a $1500 \mathrm{~m}$ climb or a 100 miler you know they've got a passion for the sport. For me it's part of my identity as a rider, I like to keep my figures up to show what type of rider I am" (Keith 32).

The public persona or identity that Strava data projected was an element that some riders took seriously, as they believed it reflected their credibility and commitment as cyclists. This again being a factor in maintaining long-term engagement in the app and the activities it supports. The implications for health are clear with the 'cognitively corrupted' (Michael, 2009) cyclist instilled with a digital imperative to ride and accumulate. A compulsion fuelled further by competition with peers and the sharing of data and achievements via other social networks.

\section{Training and performance}

Strava provides a sophisticated training aid for cyclists. In addition to reporting ride achievements and visually mapping the route and terrain covered whilst riding, the app also provides a performance analysis. This includes features such as heart rate, power and cadence. The data is quantified and inscripted providing readouts on the individual ride and their performance over time. Riders can observe a training log of all the activities that they have undertaken as well as a cumulative graph charting their fitness and fatigue, based upon an impulse response model calculated from the training load and heart rate measurement. For Phil below the benefits were clear.

"I use it for training. Before Strava it was literally a pen and paper job. Now I've so much information all in one place. Heartrate, cadence, performance and I can see the results and understand what works for me." (Phil 37)
For Phil, Strava represents a new form of health surveillance providing a deeper sense of understanding about his body and performance which he uses to improve his fitness levels. Steve's quote below demonstrates this greater awareness, further emphasising that everyday self-quantification is no longer limited to a set of bathroom scales nor is sophisticated performance monitoring the preserve of professional athletes or diligent amateurs - it is available to all.

"I never trained [I] just rode. Now I structure it, a big ride followed by a rest day or recovery ride. The commute feeds into this. I ride to work in a specific heart rate zone or cadence focusing on my allround health as a cyclist. If I plateau I think 'what else can I do?' 'the gym or the pool and do some core work?' (Allan 44)

From a health and fitness perspective this is important. Strava should not be dismissed as an app that functions purely on gamification. Users' engagement with the app also leads to a greater appreciation of the benefits of a healthy diet and lifestyle as well as providing an insight into physiological health.

\section{Sociability and surveillance}

Online sociability and ride sharing has provided a new connection between riders. Cyclists from this study commented that by logging their rides they felt like part of the club community even when their club riding was curtailed by other commitments. Jake's diary entry and Dave's interview extracts below illustrate the role that Strava plays in keeping cyclists connected on a daily basis.

"Plenty of KUDOS for today's ride. First century of the year and with added hills. It's odd to get kudos for a 3 mile commute although plenty still do. I think it's more social than anything like when you doff your cap to a passing cyclist. Mutual respect for getting out on two wheels" (Jake 32)

"Sunday mornings aren't good for me. I ride alone out of convenience and sometimes preference but I can stay in touch with the guys [from the club] on Strava - so they know I'm still getting out. It's less of a shock when I do actually make it along” (Dave 42)

The social contact enabled through various apps was regarded as largely positive, facilitating likeminded and athletically compatible riders to organise rides around the formal club ride calendar. Social media pages on Facebook or Twitter further enhanced online sociability. Potential club members could also observe rides undertaken by the club to gauge whether they were fit enough to join the club activities - A function also useful for club members, particularly if a ride was organised by a particularly strong rider/subset of riders from the club.

Whitson (2013) highlights that "playing a game is inherently social. One cannot play alone". Whilst this is true Strava does allow lone competition but over time the digital surveillance that facilitates the gamification of the pursuit can, for some, become unpleasant.

"Whenever you're cycling [it's] in the back of your mind, the segments, your speed, the miles what the ride will be called. It never really goes away for long, it interferes with the ride". (Phil 37)

Drawing parallels to Michael's (2009) research on mobile phone use in the countryside whereby hillwalkers were more likely to utilise rescue service because of the technology. Cyclists become similarly 'cognitively corrupted' by entering into the highly scripted assemblage of tracking, logging and competition with its associate self and peer surveillance. The digital imperative of Strava provides both enjoyment but can also lead to dissatisfaction.

"Sometimes I just want to ride my bike, but you can't do that anymore, everything is monitored and recorded. You could leave your Garmin at home but I never do". (Joanne 24)

Some riders, including Steve below, have actively stepped away from Strava citing displeasure with the surveillance and its impacts on 
the cycling experience.

"It's hard to stop, it becomes part of the routine, it becomes part of the ride. It's been a revelation I've had to learn to enjoy biking again for what it is and to me it's better without the pressure of Strava. The first time out it's odd a feeling like something's amiss like constantly remembering that you've forgotten your pump or helmet. But you soon get back to normal." (Steve 42)

Several riders had become concerned because the surveillance of the ride was having an impact upon their enjoyment of the activity.

"Cycling is all about freedom from constraints the flow of the road and the ride. The route should be inspired by how you feel where YOU want to go at that particular time. [With Strava] I found [that] more and more my route choice was driven by that damn app. And I wasn't enjoying it. I was aware that others would be looking at my rides and judging." (Ken 39)

The above illustrates the end of the Strava 'cycle of use' for Ken, like with Steve above, the competition and rivalry that he initially enjoyed became unpleasant, self and peer surveillance that was negatively impacting upon his stories like this were backed up in reflective diary entries. Riders' relationship with Strava was often contradictory on one hand citing the pleasure of achievement whilst on the other displeasure of constant surveillance and competition. Riders such as Ken opted for different ride logging apps without the competitive and social element - none of the riders in this study, despite numerous instances of surveillance fuelled angst, admitted to stopping logging their rides completely.

Understanding the Strava cycle of use is important both to the continuation of the app and for the employment of gamification for health policy/initiative ends - As Coombes and Jones (2016: 68) in a recent article in this journal point out "increasing levels of engagement may substantially improve the effectiveness of the interventions". This article has helped chart the dynamics of engagement and thus represents an important resource and approach for those looking to encourage participation through the gamification of activity.

\section{Conclusion}

We are moving into a time when our lives, leisure and fitness activities are increasingly augmented by technology. Cycling provides an example of one area where technologies and practices are changing. Fitness tracking apps like Strava influence cyclists' practices and continue to endure post performance, via tracking, quantification and inscription. A digital record of the ride is produced to share, discuss and compare. The riders involved in this study were drawn towards these newly visible classifications with the associated competition. This resulted in a digital imperative whereby persuasive scripts acted to modify practice with every ride presenting an opportunity to compete. The mechanisms that draw cyclists in to this competitive arena are simplistic but effective and compelling - increasing the intensity, frequency and duration of activity in my sample. The gamification helps cyclists to establish new patterns and regimes of cycling and training in order to motivate themselves to maintain and improve fitness and health. Challenges, training and profile development functions help maintain activity and engagement with the app and pursuit. Thus providing both the long term draw and sophistication needed to improve their health and in turn their performances.

For those with an interest in health promotion this paper provides useful qualitative detail about how practitioners engage with activity tracking apps. This context is important because outdoor exercise, and cycling in particular, has represented a central element of Government health schemes such as 'Change 4 Life'. However, commentators have highlighted that policy initiatives often fail to conceptualise how active leisure practices develop and spread thus failing to achieve positive outcomes (Eden, 2016). Through qualitative research this paper demonstrates the dynamics of sociotechnical change and engagement with technology in contemporary cycling. The research illustrates that a gamified fitness app and health tracker can be used successfully to enhance the activity of an engaged community of enthusiasts. By exploring cyclists performed relations with technology, or as Bradley and Armand (2006) refer to it their technicity, researchers are better able to observe and understand the impact that engaging with apps have upon activity, health and well-being. This research has sought to provide insights that pave the way to instigating, normalising and sustaining active lifestyles as well as suggesting methods of engaging the inactive. This is a valuable start but bridging the gap between health policy aims and positive outcomes necessitates more research of this nature.

The appeal of fitness tracking apps is not universal, some actively oppose or resist them, whilst others cite displeasure from the peer evaluation and surveillance that the apps entail and promote. Engagement with apps influences activity and whilst this may appear to be self-perpetuating others argue that changes are intended and scripted by the apps, who are ultimately seeking increased revenues through engagement (Timmer et al., 2015). There are fears that apps such as Strava could create hyperaware cyclists driven by obsession rather than enjoyment (Hargrave, 2013) resulting in problems relating to overtraining, overexertion and risk taking (Bader, 2013). In addition to these established concerns, this paper identifies that increased frequency and/or durations of cycling can have a negative effect on familial relationships and conjugal contributions. This in turn has the potential to limit health and leisure opportunities of others (see also Nomaguchi and Bianchi, 2004). Thus whilst gamification can promote enjoyment and motivation it can also lead to negative consequences and whilst these are often the subject of ridicule, forming part of cyclists' banter, they need further critical consideration and research.

\section{Acknowledgements}

First, I would like to thank all of the cyclists who participated in this research. I would also like to thank the three anonymous reviewers and the special issue co-organisers all of whom provided very useful comments on earlier iterations of this paper. Finally, I would like to thank Staffordshire University who provided the funding for this project through their Vice Chancellor's Small Research Grant Scheme.

\section{References}

Bader, C., 2013. Strava and User Safety: How Far Does Business Responsibility Go? Guardian (October 21st 2015). 〈http://www.theguardian.com/sustainable-business/ strava-safety-bicyclists-responsibility-lawsuit).

Barratt, P., 2011. Vertical worlds: technology, hybridity and the climbing body. Soc. Cult. Geogr. 12, 397-412.

Barratt, P., 2012. 'My magic cam': a more than representational account of the climbing assemblage. Area 44, 46-53.

Bradley, A., Armand, L. (Eds.), 2006. Technicity. Charles University Press, Prague.

Butryn, T., Masucci, M., 2009. Traversing the matrix Cyborg athletes, technology and the environment. J. Sport Soc. Issues 33, 285-307.

Coombes, E., Jones, A., 2016. Gamification of active travel: a pilot evaluation of the Beat the Street physical activity intervention. Health Place 39, 62-69.

Dansie, S., 2013. Has Strava Replaced the Sprint for the Village Sign? 〈http://www. bikeradar.com/road/gear/article/has-strava-replaced-the-sprint-for-the-villagesign-38681/>.

Department for Transport (DfT), 2014. Value for Money Assessment for Cycling Grants. 〈https://www.gov.uk/.../uploads/.../vfm-assessment-of-cycling-grants.pd〉.

Eden, S., 2016. Environmental Publics. Routledge, London.

Essany, M., 2013. mHealthWatch. Webcite Mobile Health Care Apps Growing Fast in Number, April 15. 〈http://mhealthwatch.com/mobile-health-care-apps-growingfast-in-number-20052/ $\rangle$.

Fishman, E., Schepers, P., Kamphuis, C.B.M., 2015. Dutch cycling: quantifying the health and related economic benefits. Am. J. Public Health 105 (8), 13-15.

Fogg, B.J., 2003. Persuasive Technology: Using Computers to Change What We Think and Do. A volume in Interactive Technologies. Morgan Kaufmann Publishers Inc., San Fransisco.

Hamari, J., Koivisto, J., Sarsa, H., 2014. Does gamification work? A literature review of empirical studies on gamification. In: Proceedings of the Hawaii International Conference of System Science. Waikoloa, HI, pp. 3025-3034. 
Hargrave, J., 2013. The silly self importance of Strava. Utah Adventure J.http:// utahadvjournal.com/index.php/the-silly-self-importance-of-strava.

Hitchings, R., Latham, A., 2016. Indoor versus outdoor running: understanding how recreational exercise comes to inhabit environments through practitioner talk. Trans. Inst. Br. Geogr.. http://dx.doi.org/10.1111/tran.12138.

Ipsos Mori, 2016. Ipsos Connect Tech Trascker. 〈https://www.ipsos-mori.com/ researchpublications/publications/1836/>.

Jones, P., 2005. Performing the city: a body and a bicycle take on Birmingham, UK. Soc. Cult. Geogr. 6, 813-830.

Kirsch, S., 1995. The incredible shrinking world? Technology and the production of space. Environ. Plan. D: Soc. Space 13 (5), 529-555.

Latham, A., Wood, P.R.H., 2015. Inhabiting infrastructure: exploring the interactional spaces of urban cycling. Environ. Plan. A 47, 300-319.

Latour, B., 1999. Pandora's Hope. Essays on the Reality of Science Studies. Harvard University Press, Cambridge, MA.

Leary, M.R., 1992. Self-presentational processes in exercise and sport. J. Sport Exerc. Psychol. 14, 339-351.

Lister, C., West, J., Cannon, B., Sax, T., Brodegard, B., 2014. Just a fad? Gamification in health and fitness apps. JMIR Serious Games 2 (2), 1-12.

Lorimer, H., 2005. Cultural geography: the business of being more than representational. Prog. Hum. Geogr. 29, 83-94.

Mercer, D., 2007. The dangers of autobiographical research: a response to Purcell. Antipode 39, 571-578.

Michael, M., 2009. The cellphone-in-the-countryside: on some of the ironic spatialities of technonatures. In: White, D., Wilbert, C. (Eds.), Technonatures: Environments, Technologies, Spaces, and Places in the Twenty-first Century. Wilfrid Laurier University Press, Waterloo, 85-104.

Sailer, M., Hense, J., Mandl, H., Klevers, M., 2013. Psychological perspectives on motivation through gamification. Interact. Des. Archit. J. 19, 28-37.

Mintel, 2015. Bicycle Accessories - UK - June 2015. 〈http://academic.mintel.com〉

Mintel, 2016. Bicycles - UK - March 2016. 〈http://academic.mintel.com〉.

Nomaguchi, K., Bianchi, S., 2004. Exercise time: gender differences in the effects of marriage, parenthood, and employment. J. Marriage Fam. 66 (2), 1741-3737. http://dx.doi.org/10.1111/j.1741-3737.2004.00029.x.

Office for National Statistics (ONS), 2014. 2011 Census Analysis - Cycling to Work. 〈http://webarchive.nationalarchives.gov.uk/20160105160709/http://www.ons.gov. uk/ons/dcp171776_357613.pdf).

Pantzar, M., Ruckenstein, M., 2015. The heart of everyday analytics: emotional, material and practical extensions in self-tracking market. Consum. Mark. Cult. 18 (1), 92-109.
Payne, H.E., Lister, C., West, J.H., Bernhardt, J.M., 2015. Behavioral functionality of mobile apps in health interventions: a systematic review of the literature. JMIR MHealth Uhealth 3 (1), 1-9.

Pooley, C., Tight, M., Jones, T., Horton, D., Scheldeman, G., Jopson, A., Mullen, C., Chisholm, A., Strano, E., Constantine, S., 2011. Understanding Walking and Cycling: Summary of Key Findings and Recommendations, Lancaster Environment Centre. 〈http://www.lec.lancs.ac.uk/research/society and_environment/cycling/ Understanding_Walking_\&_Cycling_Report_WEB $\rangle$.

Shove, E., Pantzar, 2005. Consumers, producers and practices understanding the invention and reinvention of nordic walking. J. Consum. Cult. 5 (1), 43-64.

Sparkes, M., 2013. The Internet: Worst Thing to Happen to Cycling in Years? /http:// www.telegraph.co.uk/men/active/recreational-cycling/10270524/The-internetworst-thing-to-happen-to-cycling-in-years.html $\rangle$.

Spinney, J., 2006. A place of sense: a kinaesthetic ethnography of cyclists on Mont Ventoux. Environ. Plan. D: Soc. Space 24, 709-732.

Spinney, J., 2011. A chance to catch a breath: using mobile video ethnography in cycling research. Mobilities 6 (2), 161-182.

Sport England, 2013. Active People Survey 8 Sport England, London.

Steinbach, R., Green, J., Datta, J., Edwards, P., 2011. Cycling and the city: a case study of how gendered, ethnic and class identities can shape healthy transport choices. Soc. Sci. Med. 72 (7), 1123-1130.

Strava, 2016. [ONLINE] Available at: 〈https://www.strava.com〉

Sutch, A., Scott-Bayfield, A., Carpenter, D., 2015. The Sport and Physical Activity Sector: An Overview. Sportsgroup. 〈http://fitmediafitness.co.uk/wp-content/uploads/2015/ 07/Sportsgroup-Overview.pdf).

Thrift, N., French, S., 2002. The automatic production of space. Trans. Inst. Br. Geogr. 27, 309-335.

Timmer, J., Kool, L., Van-Est, R., 2015. Ethical challenges in emerging applications of persuasive technology. Persuasive Technology Lecture Notes in Computer Science. Vol. 9072, pp. 196-201.

Verhoeff, N., 2012. Mobile Screens. The Visual Regime of Navigation. University Press, Amsterdam.

Wallace, W., 2012. Strava - From the Beginning. 〈http://cyclingtips.com.au/2012/02/ strava-from-the-beginning/ $>$ (accessed 10.03.16.).

Whitson, J., 2013. Gaming the quantified self. Surveill. Soc. 11, 163-176.

Woodcock, J., Lovelace, R., Tainio, M., 2014. A53 cycling health and climate: what are the circumstances under which cycling can contribute to substantive greenhouse gas emission reductions and whose travel should be targeted to achieve the biggest health and climate benefits? J. Transp. Health 2 (2), 32. 